\title{
COVID-19 and Indian Pediatrics
}

All of us are experiencing the effects of the Coronavirus (COVID-19) pandemic - the proactive response of the Indian government has been widely appreciated. The associated lockdown; although essential, has led to difficult times for the journal, as it was not possible for the journal staff to visit the office, and consequently the editing of accepted manuscripts and other associated work of the editorial office had to be put on hold. Thankfully, the April issue was already near completion and the required editorial work could be done on soft copies. Similarly, the Editorial Manager website continued functioning uninterrupted and we could continue handling new and revised submissions. Our editors and reviewers, all busy clinicians and at the forefront of the COVID-19 response, kept on contributing to the journal work, so that manuscript handling continued without a hitch. However, due to the lockdown, the printing press could not continue operations, and the print issue would be delayed. But, we would be sending the electronic issue to all subscribers of the e-copy, and also uploading the full April issue at our website timely. It is likely that this issue may have more than its share of printing errors, as proof-reading could not go ahead as per schedule. However, bringing out the April issue in time was our primary objective in these times of hardship, which we could achieve with the combined efforts of the journal team and our printers, Cambridge press.

On the brighter side, after an expedited review process, we are publishing two special articles on intensive care unit (ICU) management of children with COVID 19 infection in this issue. The pre-prints were uploaded at the journal website on 29 March, 2020 (www.indianpediatrics.net.covidpapers). We hope that these will be helpful to the pediatricians in handling affected children, as and when they present. In the Correspondence section, a reader has raised an interesting issue vis-a-vis measles vaccination and protection from COVID-19.

We aim to continue our practice of last more than fifty years of regular publication of journal issues, and look forward to your continuing support for all journal activities!

Devendra Mishra

Editor-in-Chief ip.editor@iapindia.org 